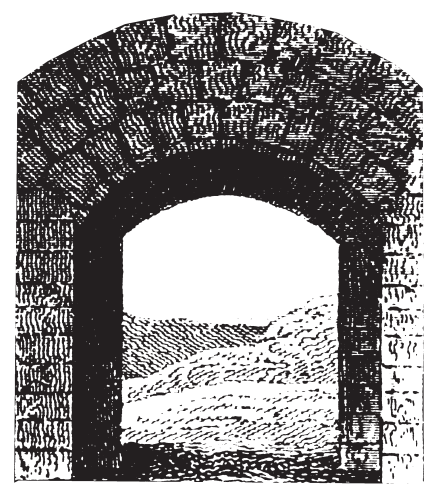

\title{
INFORMACIÓN BIBLIOGRÁFICA Y NOTICIAS
}

\section{TESIS DIDÁCTICAS}

\section{Enseñanza y aprendizaje del conflicto armado en Colombia. Prácticas docentes y conocimiento escolar}

\section{Autor: Juan Carlos Ramos Pérez}

Universidad: Universitat Autònoma de Barcelona

Departamento: Didàctica de la Llengua i la Literatura, i de les Ciències Socials

Fecha de lectura: 13 de noviembre de 2017 Programa de doctorado: Doctorado en Educación

Dirección: Joan Pagès i Blanch

El conflicto armado, la guerra, ya sea entre estados o habitantes de un mismo territorio, ha sido una de las grandes constantes en la historia de la humanidad, lo que justifica y hace necesario su tratamiento en las aulas de los distintos niveles educativos, desde educación primaria hasta la universidad. El estudio de la guerra debe abordarse en toda su complejidad (desde víctimas y asesinos hasta los intereses que se crean en torno a ellas), y debería tener como finalidad última la formación en valores democráticos del alumnado. Los conflictos -y muy especialmente los internos- son cuestiones socialmente relevantes, que provocan polémicas y controversias en las sociedades actuales, pero que, a su vez, generan un enorme interés entre la ciudadanía, lo que explica la extraordinaria y abundante producción historiográfica que originan.

Es por este motivo que no podemos más que aplaudir la tesis doctoral de Juan Carlos Ramos, dirigida por Joan Pagès, que se ha aproximado al conflicto armado colombiano, uno de los más duraderos en el tiempo, más recientes, y que más dolor y sufrimiento han provocado entre la ciudadanía. La investigación de Ramos puede ser calificada de valiente, arriesgada y comprometida. Es valiente porque la cuestión abordada no es cómoda para los investigadores, los docentes y la ciudadanía colombiana en general; es arriesgada porque apuesta por llevar el conflicto al aula, un conflicto que ha dividido a la sociedad colombiana y, por ende, al alumnado; y es comprometida porque solo desde el compromiso con la profesión docente y con los principios y valores democráticos es posible apostar por esta temática y por encontrar explicaciones complejas y ajustadas a la realidad histórica que nos permitan vislumbrar un futuro más prometedor.

A lo largo de nueve capítulos, Juan Carlos Ramos plantea cuestiones, tales como por qué y para qué enseñar la guerra, y cómo hacerlo para que genere conocimiento histórico. Ramos manifiesta la paradoja de que, pese a la presencia constante y permanente que tiene el conflicto en la sociedad colombiana (incluida en la opinión pública y en las decisiones políticas), esa realidad no se extrapola a las aulas. Todo lo contrario. La escuela se resiste a analizar, estudiar y enseñar el conflicto a pesar de los beneficios que podría reportar a la sociedad colombiana. Según este autor, esta situación es resultado, por un lado, de la 
poca conciencia de los gobiernos y de las autoridades educativas $\mathrm{y}$, por otro lado, de la precaución y la reticencia de los docentes y de los equipos directivos de los centros educativos, que marginan una temática problemática para la sociedad.

Una de cuestiones más importantes que se abordan en el trabajo está relacionada con la finalidad de la enseñanza de la guerra en las aulas. Coincidimos con Ramos en que la docencia respecto a las contiendas debería tener como fin último comprender que los conflictos bélicos se sustentan en intereses ideológicos, políticos y económicos de una parte de la sociedad. Y, además, debería derivar en acciones concretas que reflejen cambios actitudinales y no solo cognitivos por parte del alumnado, relacionados con valores y principios democráticos como el respeto a la diversidad, la convivencia, la libertad, la igualdad o la solidaridad. La enseñanza de la guerra en las aulas debe ayudar tanto a concienciar en el drama humano como a paliar algunos de sus efectos más dramáticos, pero, fundamentalmente, debe cimentar una cultura de la paz y, con ella, propiciar acciones ciudadanas para evitar la aparición de los conflictos bélicos.

Desde nuestro punto de vista son varios los aciertos y las aportaciones que realiza la investigación de Juan Carlos Ramos. En primer lugar, el autor no se limita a describir y narrar un hecho histórico dramático para la sociedad colombiana - la presencia cotidiana y duradera en el tiempo de la violencia en las vidas de toda la ciudadanía-, sino que diseña una investigación didáctica a partir de la Teoría Fundamentada y el análisis del discurso que le sirve para establecer categorías de estudio y extraer conclusiones sobre el conocimiento que tienen los docentes del conflicto y sobre cómo construye el alumnado el conocimiento sobre el hecho histórico. Plantea además una propuesta didáctica para trabajar el conflicto en las aulas de ESO y Bachillerato que tiene al alumnado como agente protagonista de la construcción de su propio conocimiento. Y todo ello cimentado en un marco teórico que permite entender y reconocer los supuestos de los que parte y en los que se basa la investigación. A este respecto, entendemos que la ausencia de análisis cualitativo es sin duda uno de los grandes problemas de credibilidad que presenta la investigación en Didáctica de las Ciencias Sociales, ya que gran parte de lo que decimos no es corroborado por el método científico, sino que queda como una narración-descripción de situaciones didácticas.
En segundo lugar, Ramos destaca la fuerte carga de emotividad de esta temática en las aulas - y no solo en Colombia- que provoca miedo y aprehensión en los docentes, que se autocensuran al tratar este contenido por miedo a la respuesta que tendrán sus propuestas en las casas de los estudiantes. Para superar esta tensión y polémica — dice Ramos- los docentes priman la formación en habilidades y valores sociales como la convivencia y la tolerancia, en lugar de problematizar el conflicto para explicar la realidad política del país. A pesar de incluir pocas entrevistas en el texto (una de las pocas debilidades de la investigación), Ramos nos aproxima a unos docentes colombianos cuyo trabajo se puede enmarcar en la teoría curricular crítica, pues, a pesar de que sus metodologías son expositivas, se comprometen con la temática de estudio y pretenden que su trabajo en el aula trascienda a la sociedad, mejorándola mediante la formación de una ciudadanía crítica y comprometida con la paz. Hay que destacar sobre todo su valentía porque, aunque en la escuela no hay un discurso oficial, sí lo hay en la opinión pública y en las instituciones políticas que entienden el conflicto como un enfrentamiento entre buenos y malos, y de ahí que reciban presiones y amenazas de los simpatizantes de los distintos protagonistas de la contienda. Además, como ocurre en otros sistemas educativos - como es el caso de España-, los docentes manifiestan dificultades para innovar en sus prácticas docentes, por la escasez de tiempo para discutir, preparar y diseñar propuestas didácticas y curriculares y por la gran cantidad de contenidos históricos que tienen que abarcar en poco tiempo.

Una de las conclusiones más interesantes de la investigación es que el alumnado muestra una fuerte resistencia a modificar su conocimiento informal sobre el conflicto armado, adquirido en la interacción con el medio social y cultural, destacando el autor la fuerte influencia de los medios de comunicación en la opinión generalizada del alumnado. Además, el conocimiento formal -el que se fundamenta en el discurso historiográfico- se percibe como útil únicamente en el contexto del aula (para superar una evaluación o para el desarrollo de actividades escolares), pero no para dar explicaciones propias del conflicto, lo que manifiesta — según Ramosuna división entre el saber escolar y el saber informal, que está mucho más influenciado por el campo de las emociones y los sentimientos. En relación con esto, el autor concluye que el alumnado colombiano apenas tiene en cuenta las causas y expli- caciones estructurales del conflicto, y sí acude, en cambio, a los testimonios de las víctimas, a los discursos políticos y de opinión, y a los productos mediáticos para construir sus relatos sobre la contienda, así como a las historias televisivas (series de ficción) y a los cuentos infantiles.

También nos dice Ramos que un proyecto educativo bien dirigido y coordinado puede generar pensamiento histórico $\mathrm{y}$, por tanto, pensamiento crítico, independientemente del contexto social, cultural y económico del alumnado. Y considera que la mejora docente depende muy especialmente del profesorado, del convencimiento de que sus prácticas generan mejores aprendizajes, y no tanto de las modificaciones curriculares o la disposición de nuevos y mejores materiales didácticos.

En definitiva, el trabajo de Juan Carlos Ramos apuesta por incluir el conflicto armado de Colombia en las aulas, con toda su complejidad sobre causas, actores, escenarios y consecuencias, con el objetivo de formar una ciudadanía comprometida con la resolución pacífica y negociada de los enfrentamientos y, sobre todo, para encontrar una salida política a una confrontación que, además del daño producido a las víctimas, ha dejado dividida y enfrentada a la sociedad colombiana actual, que debe ahora decidir cómo gestionar la memoria del conflicto: apostando por un relato simplista que habla de buenos y malos, o trascendiendo esa visión maniquea y buscando un consenso sobre las múltiples y variadas causas que permiten explicar tantos años de violencia. Esta última alternativa requerirá la toma de conciencia histórica y política de las nuevas generaciones de colombianos. Y es aquí donde la escuela tiene mucho que aportar, según remarca continuamente el Doctor Ramos, con la apuesta docente por metodologías activas, con la utilización de la memoria para motivar e interesar al alumnado, y buscando una explicación histórica del pasado más compleja y que llegue a constituir una conciencia histórica. Como dice Ramos, solo una ciudadanía que ha comprendido críticamente su pasado puede comprender su realidad social y actuar decididamente en su cambio desde una perspectiva democrática.

Santiago Jaén Milla Universidad de Jaén sjaen@ujaen.es 


\section{Enseñar y aprender historia con el patrimonio. Evaluación cualitativa en museos de Asturias}

\section{Autor: Miguel Ángel Suárez Suárez}

Universidad: Universidad de Oviedo

Departamento: Departamento de Ciencias

de la Educación

Fecha de lectura: 12 de mayo de 2017

Programa de doctorado: Investigación e Intervención Socioeducativa

Dirección: Roser Calaf Masachs y Carmen Fernández Rubio

No es habitual que una tesis presentada por compedio de publicaciones tenga un corpus teórico-metodológico tan extenso: 519 páginas. Este formato de presentación tiende a estar limitado por la normativa o recomendación de cada universidad. Y suele pasar por realizar un informe breve, adjuntando, a lo sumo, los artículos mejor posicionados. Por el contrario, desde ese aspecto formal-burocrático, esta tesis parte con voluntad de cambio y con cierta declaración de intenciones. Sorprende desde el inicio, con un trabajo original, bien fundamentado y estructurado en cuanto a su cuerpo y forma de presentación. Aprovecha la potencialidad del recopilatorio de sus publicaciones para exponer con detenimiento la dimensionalidad estructural del proyecto de investigación. Y, a su vez, logra depurar la extensión, en ocasiones tediosa, de estos trabajos científicos y servirse, asimismo, de ese carácter divulgativo de los artículos publicados. Da lugar así a un razonamiento exhaustivo y crítico sobre Enseñar y aprender Historia con el patrimonio y sobre su Evaluación cualitativa en museos de Asturias, manifestando una simbiosis eficaz y elocuente de ambos formatos de maquetación.Se inicia el viaje con un mapa de nuestro país que sirve de guía para desvelar la producción científica del área de la Didáctica de las Ciencias Sociales en su investigación educativa sobre el patrimonio. La siguiente parada comienza con el dilema «¿Para qué la Historia?», excusa perfecta para realizar un recorrido epistemológico del potencial de esta materia, desde la óptica interna de expertos, hasta la percepción de los alumnos y el contexto actual. Para ello, se recoge y se hila el argumentario de reconocidos autores como Altamira (1895), Bloch (1952), Fontana (1975), Valdeón (1988), Lerena (1991), Carnoy (1999), Audigier (2012), Prats (2016), entre muchos otros. El marco teórico se cierra con el tercer capítulo: enseñar y aprender historia con el patrimonio, que expone las posibilidades didácticas para conectar el pasado con el presente mediante la activación educativa del patrimonio. $\mathrm{La}$ transferencia de esta aproximación teórica se encuentra en Suárez (2012, 2014a y 2014b).

El sobresaliente cum laudem debiera tener carácter vinculante con la calidad del trabajo de tesis, ofreciendo, de este modo, garantías de su investigación. Y, en este caso, así sucede, tal y como indica De Miguel (2010), al responder a cuatro máximas que consolidan esta afirmación:

Definición del problema con claridad; revisión crítica y pertinente de la literatura, como se ha comentado.

Especificidad metodológica: adecuación al marco teórico, novedoso, con la inclusión de la evaluación como mecanismo de rigor para la toma de decisiones en el área de la Didáctica del Patrimonio; la ampliación del desarrollo de conocimiento científico que se venía realizando hasta el momento y la incorporación de procedimientos de corte cualitativo (entrevistas semiestructuradas a los responsables del Servicio Educativo de los museos), siguiendo la línea proyectada por el proyecto ECPEME (Evaluación Cualitativa de Programas Educativos en $\mathrm{Mu}$ seos Españoles). Pero como complementaridad metodológica se usan el cuestionario para conocer la opinión del profesorado y, validados estadísticamente, asimismo, dos protocolos de observación, uno de ellos referido a la museografía, elaborado ad hoc, y el otro relacionado con la comunicación del educador. Todo ello, para conocer la relación entre escuela-museo, analizando tanto el papel escolar como la voz de los museos y la observación del investigador.

Análisis de resultados: mediante la triangulación como rutina analítica se describen y se significan los datos sobre el diálogo escuela-museo. Así, se concluye que esta comunicación interinstuticional parte de la demanda de ambos por dialogar, pero el profesorado supedita este contacto a la inciativa del museo, sobre quien recae la acción educativa. Los primeros demandan al museo más materiales didácticos para preparar la visita con mayor vinculación curricular, así como más actividades de difusión y de encuentro entre el profesorado y los museos. Estos últimos, por su parte, demandan un contacto más fluido e interactivo con los centros escolares, tanto para establecer unas bases previas al desarrollo de la visita, como, posteriormente, para conocer el continuum de ese aprendizaje. Se hace necesario no sumar al otro a nuestras propuestas, sino que escuela y museo desarrollen acciones conjuntas. Suárez considera que la escasa presencia de la Didáctica del Patrimonio en la formación del profesorado pudiera estar influyendo en esta relación, en la que cobra especial relevancia el buen hacer de cada enseñante, en numerosas ocasiones lastrado por la diversidad de itinerarios formativos de unos educadores de museo que muchas veces no tienen relación directa con el ámbito educativo. Los propios educadores señalan en las entrevistas esta necesidad formativa, y los resultados de las observaciones muestran diferencias significativas entre aquellos con formación disciplinar (Geografía, Historia o Historia del Arte) y los de Turismo; si bien, el objetivo no es reivindicar un título u otro, sino dar respuesta a una necesidad de desempeño profesional. Esta circunstancia también podría verse afectada por la falta de evaluación educativa de las actividades, que es otra de las limitaciones señaladas en el museo, que impide el conocimiento detallado de su labor didáctica y la proyección laboral.

La Tesis ratifica que sigue siendo una realidad el rol pasivo del grupo de escolares, quienes, si bien responden a las preguntas que formulan los educadores del museo, rara vez plantean otras cuestiones adyacentes que podrían manifestar un trabajo previo en el aula. La planificación de la visita es otra tarea pendiente, no habiéndose observado ningún caso en el que se presentaran los estudiantes con material adicional o se les hubieran dado pautas explicativas a seguir durante la visita. No obstante, los educadores del museo sí que constatan la presencia de grupos escolares que vincularon, de manera explícita, la visita con el desarrollo curricular, recordando con agrado esta circunstancia o profesores que, puntualmente, relacionaronla visita con cuestiones tratadas en el aula.

Nivel de impacto: se estima en función de su publicación en revistas de prestigio. La transferencia de esta investigación se ha efectuado en varias publicaciones: Revista de Educación (2014), Fonseca, Journal of Communication (2017), Didáctica de las Ciencias Experimentales y Sociales (2012) o Clío: History anda History Teaching (2013) y Her\&Mus (2011). Mérito a destacar este, teniendo en cuenta las peculiaridades en el área de la Didáctica de las Ciencias Sociales, donde el rango de publicaciones con presencia en JCR es escaso. También se debe añadir su coautoría en dos monográficos de Trea, editorial de referencia en nuestro país en materia de patrimonio, museografía o museología.

Por último, se proyectan una serie de propuestas en el ámbito de la investigación. 
Entre estas, el desarrollo de estudios sobre el profesorado mediante grupos de discusión o entrevistas que ahonden en su visión o interés por el museo, en los problemas y las demandas; o, asimismo, seguir profundizando en el trabajo de los educadores, como desarrollo científico del área de Didáctica del Patrimonio, pero también como resignificación profesional. El objetivo sería poder implementar en un futuro experiencias didácticas en el museo orientadas a la mejora educativa.

En definitiva, se ha conseguido equilibrar el contexto de investigación considerando las partes (educadores del museo, profesorado, museografía, desarrollo de la visita) y el todo (la educación, el aprendizaje y la evaluación); todo ello para sumar argumentos en la concepción del museo como un espacio idóneo para la enseñanza de la Historia.

\section{REFERENCIAS BIBLIOGRAFICAS:}

ALTAMIRA, R. (1895). La enseñanza de la Historia. Madrid: Librería de Victoriano Suárez.
AUDIGIER, F. (2012). Postfacio: Prolongar y construir un debate necesario. En P. PERRENOUD (ed.), Cuando la escuela pretende preparar para la vida. ¿Desarrollar competencias o enseñar otros saberes? (pp. 219224). Barcelona: Graó.

BLOCH, M. (1952). Introducción a la Historia. México: Fondo de Cultura Económica.

CARNOY, M. (1999). Educación, economía y estado. En M. Fernández Enguita (ed.), Sociología de la educación (pp. 151-174). Madrid: Ariel.

DE MIGUEL, M. (2010). La evaluación de tesis doctorales. Propuesta de un modelo. $R E$ LIEVE, 16(1), 1-18. Recuperado de: http:// www.uv.es/RELIEVE/v16n1/RELIEVE v16n1_4.htm

FONTANA, J. (1975). La Historia. Barcelona: Salvat.

LERENA, C. (1991). Escuela, ideología y clases sociales en España. Crítica de la sociología empirista de la educación. Barcelona: Ariel.

PRATS, J. (2016). Combates por la Historia en la educación. Discurso de investidura como Doctor Honoris Causa por la Universidad de Murcia, pp. 31-49.

SUÁREZ, M. Á. (2012). Concepciones sobre la Historia en Primaria: la epistemología como asunto clave en la formación inicial de maestros. Didáctica de las Ciencias Experimentales y Sociales, 26, 73-93.

SUÁREZ, M. Á. (2014a). ¿Aprender el patrimonio o aprender con el patrimonio? En R. CALAF, M. Á. SUÁRES y S. GUTIÉRREZ, La evaluación de la acción cultural en museos (pp. 51-70). Gijón: Trea.

SUÁREZ, M. Á. (2014b). El Museo del Ferrocarril de Asturias. En R. CALAF y M. Á. SUÁRES (coords.), Acción educativa en museos: Su calidad desde la evaluación cualitativa (pp. 107-136). Gijón: Trea.

VALDEÓN, J. (1988). En defensa de la Historia. Valladolid: Ámbito.

Sué Gutiérrez Berciano Universidad de Oviedo

«Y la arqueología llegó al aula. La cultura materia y el método arqueológico para la enseñanza de la historia y el patrimonio», coordinado por el Dr. Alejandro Egea, la Dra. Laura Arias Ferrer y el Dr. Joan Santacana, recoge, en los dieciséis capítulos que componen el título, diversas experiencias, visiones y propuestas educativas de arqueología, tanto nacionales como internacionales, gracias a los treinta y un profesores que participan en la publicación.

A modo de introducción, el primer capítulo aporta argumentos para reflexionar sobre la importancia y la necesidad de la presencia de esta disciplina en las aulas. Pero, a pesar de los aspectos positivos que comporta en el alumnado a niveles conceptual, procedimental (contribución a las habilidades de pensamiento histórico) y actitudinal ( desarrollo personal, en cuanto al trabajo en equipo; o puesta en valor del patrimonio, que favorecerá la conservación de los bienes), existen una serie de aspectos dentro de los elementos concretos de la práctica educativa (el currículo, los libros de texto y el docente) que pueden limitar la presencia del trabajo en el aula de esta disciplina. Tales aspectos son analizados en el segundo capítulo en relación con la Educación Secundaria Obligatoria.

En esta misma línea, el capítulo de los autores Bev Forrest y Dave Weldrake analiza estos tres elementos de la realidad escolar, en concreto en el contexto de la educación primaria inglesa, para, posteriormente, mostrar un estudio de caso de una propuesta para alumnado de entre siete y nueve años.

Así, en este tercer bloque compuesto de cuatro capítulos se nos presentan diversas experiencias activas de aprendizaje con escolares en parques arqueológicos, como la Building Blocks of History, en el parque 
de historia local de Riverside FarnsleyMoremen Landing (Louisville KY, Estados Unidos), dirigida a estudiantes de todas las edades.

En el ámbito nacional se exponen dos experiencias en Educación Secundaria Obligatoria, ambas en la región de Murcia; una en Totana, en la que se trabajó en los yacimientos de La Bastida y La Tira del Lienzo; y otra denominada «Exarcom: excavación arqueológica por competencias», proyecto de innovación de la ciudad de Lorca.

Los cuatro proyectos presentados en este apartado son experiencias educativas basadas en los modelos de excavación arqueológica desarrollados en yacimientos, ya sean reales o simulados.

Pero, tal y como se muestra en el siguiente apartado, «La arqueología no es solo excavar», es posible trabajar esta disciplina a través de otros modelos didácticos.

Así, destacan los proyectos basados en la didáctica del objeto, a través de la cual se trabaja a partir del análisis de fuentes objetuales. Los capítulos 7, 8, 9, 10, 11 y 12 presentan experiencias de aprendizaje utilizando esta metodología, desde la Educación Infantil hasta la etapa de Educación Secundaria Obligatoria, en los ámbitos formal y no formal.

Además, en el capítulo «Arqueología, didáctica y nuevas tecnologías» encontramos una muestra de las posibilidades de la aplicación de las nuevas tecnologías al área del patrimonio arqueológico, como el desarrollo de Apps, páginas webs, diseños de códigos QR, la realidad aumentada o la gamificación.

Otra estrategia de aprendizaje es la arqueología experiencial. Propuestas como la de Living Archeology Weekend (en Red River Gorge, Kentucky), en la que se ofrecen las posibilidades de experimentar y de observar las tecnologías del pasado, o la del campo de La Noguera, en el que se desarrollan actividades didácticas en torno a la arqueología y a la etapa prehistórica, son algunos ejemplos aquí analizados.

Nos encontramos, entonces, ante una publicación en la que se recogen diversos modelos de proyectos educativos a través de la arqueología. A diferencia de otros textos que puedan trabajar temas similares, este volumen es especialmente rico por la variedad (tanto de enfoque como de nivel educativo del público destinatario) de ejem- plos de proyectos reales, que pueden servir como modelo al lector interesado en desarrollar experiencias similares.

Ana Portela Fontán Universitat de Barcelona

\section{App, arqueologia \& m-learning. Reconstruir, restituir, interpretar i avaluar app}

Santacana, J. Asensio, M.

Y LLONCH, N. (coord.)

Editor Rafael Dalmau, 2018, 158 páginas.

La introducción de la digitalización ha comportado importantes cambios y renovaciones en la Arqueología al permitir la creación de imágenes y planos virtuales de yacimientos arqueológicos, sin necesidad de reconstruir o restituir sobre los mismos, al tiempo que posibilita la visualización de diferentes hipótesis.

La publicación aquí reseñada, «App, arqueología \& m-learning. Reconstruir, restituir, interpretar i avaluar app», reflexiona sobre las ventajas a nivel didáctico e interpretativo de la Realidad Virtual y la Realidad Aumentada aplicada a yacimientos, al tiempo que analiza cómo deberían de ser estas imágenes para aportar un conocimiento riguroso.

En efecto, el libro que coordinan los profesores Dr. Joan Santacana, Dr. Mikel Asensio y la Dra. Nayra Llonch, y en el que participan nueve investigadores del Grup de Recerca DHiGeCS, muestra, a través de los cuatro capítulos que lo conforman, una doble reflexión: una primera sobre la potencialidad de la iconografía digital en el campo del patrimonio arqueológico; y una segunda en la que se considera cómo se podrían evaluar estas imágenes virtuales.

Así, en el primer capítulo «Arqueologia i educació» se presenta el interés pedagógico de la disciplina, dado su carácter transversal, ya que el trabajo de esta área implica el estudio de otras como Química, Física, Biología, Geología, Zoología, etc. Por otra parte, al tratarse de una disciplina popular, relacionada con la aventura y el descubrimiento, contribuye a que los alumnos puedan mantener un mayor grado de interés y motivación por su conocimiento.

En cuanto a las experiencias educativas, estas son muy variadas y comprenden las diferentes etapas de investigación de la ar- queología: desde la localización de asentamientos, la excavación, la conservación de evidencias, y secuencias hasta la reconstrucción del pasado. En lo que se refiere a la manera de acercar a los estudiantes a esta disciplina, es bastante recurrente el modelo de trabajo basado en la excavación arqueológica. También es posible a través de la utilización de laboratorios portátiles dotados de réplicas de elementos arqueológicos, o de las visitas a parques arqueológicos. Sobre este último proceder, a pesar de posibilitar un espacio en donde plantear preguntas y problemas sobre nuestro pasado, se han pronunciado distintos investigadores que ponen de manifiesto la dificultad de aprender en estos lugares.

Por este motivo, el capítulo siguiente «Arqueología i virtualitat» ahonda en los problemas que se le presenta al público ante un yacimiento. Dificultades tales como la conceptualización del espacio y el volumen, la descodificación del plano o la interpretación simultánea de varios elementos arqueológicos, o la conceptualización de tiempo relativo y absoluto. Aspectos que se interponen entre el visitante y el elemento patrimonial a la hora de crear una reconstrucción mental del pasado, frente al cual las propuestas virtuales de restituciones pueden ser de gran utilidad ya que:

- Posibilitan plantear todas las hipótesis probables y, al mismo tiempo, proporcionar datos sobre el yacimiento.

- Es posible evidenciar todas las fases de un yacimiento y analizar detenidamente los pasos que es necesario recorrer de una fase a la siguiente.

- Proporcionan la posibilidad de tratar no solamente el conjunto arqueológico sino, asimismo, el entorno paisajístico.

- Permiten exponer las bases científicas de las hipótesis, siempre que se muestre la documentación que justifica la toma de decisiones.

- Son un buen elemento para garantizar la autenticidad y la veracidad de los resultados.

(pp. 47-48)

Manifiestas las posibilidades de las imágenes virtuales, y ejemplificadas en proyectos como el de La fortaleza dels Vilars d'Arbeca (Garrigues); Sa Caleta (Eivissa), o la Ciutadella Ibèrica (Calafell) entre otros, se presentan en el capítulo «Patrimoni arqueològic i app» las características generales de las aplicaciones actuales.

Así, a partir del análisis de las propuestas existentes a día de hoy, es posible saber qué tipo de recursos muestran, el discurso 
o tratamiento de la información que se encuentra con mayor frecuencia. Además, también permite modelizar las propuestas; así, los autores proponen tres: de carácter descriptivo, interactivas y colaborativas.

Por último, a modo de cierre, se nos presenta una reflexión sobre las posibilidades de evaluación de las aplicaciones informáticas a través de los siete estudios que se incluyen en el proyecto de investigación EDU 2014-52675-R: una estrategia de investigación sobre la evaluación de app.

Se exponen las conclusiones provisionales del estudio de diferentes aspectos relacionados con propuestas de creación de imágenes virtuales aplicadas a la arqueología:

- Motivaciones y expectativas invertidas en la tecnología.

- Inclusión de los formatos analógicos y digitales.

- Uso de tablets en el museo: el Museo Arqueológico Nacional (MAN).

- Uso de tablets en un yacimiento: Cueva Pintada, Gáldar (Gran Canaria).

- Uso de app en el museo: Lázaro Galdiano (Madrid).

- Uso de app en el yacimiento: la Ciutadella Ibèrica de Calafell (Baix Penedès).

- Test de indicadores: revisión, Taller de Futuro, Propuesta de Modelo.

En conclusión, la obra permite al lector conocer las posibilidades de la digitalización en el campo de la arqueología y cómo deberían de ser estas imágenes desde la Arqueología profesional para que el visitante pudiese llegar a un conocimiento riguroso. Todo ello expuesto a través de una explicación clara, amena y concatenada de los diferentes elementos que componen el tema central de la publicación.

Ana Portela Fontán Universitat de Barcelona

\section{Enseñanza de la historia y competencias educativas}

Ramón LóPEZ FACAL, Pedro

Miralles Martínez, Joaquim Prats Cuevas (dirs.), Cosme J. Gómez

Carrasco (coord.)

Editorial Graó

Barcelona, 2017, 234 páginas.

Las realidades sociales y políticas - por lo general, agitadas- que acaparan la actualidad tienen un origen, unas causas, unas consecuencias. Si el propósito de las cien- cias sociales es comprender el mundo que nos rodea, se hace imprescindible dotar al alumnado de las técnicas y de los recursos para interpretarlo. Del todo oportuno es entonces trabajar en cómo aportar esas herramientas.

La obra colectiva que se reseña a continuación expone las conclusiones de investigaciones sobre la enseñanza de la historia y el desarrollo de las competencias educativas que se han realizado en centros de educación secundaria primordialmente, así como en universidades y en algunos colegios de primaria. Los resultados provienen de tres distintos proyectos de investigación coordinados. Ofrecen a profesores, a futuros profesores y a todo aquel implicado en la investigación didáctica un abanico de opciones de mejora en la enseñanza de las ciencias sociales. Se da respuesta a preguntas tales como qué aporta la educación histórica al conjunto de la ciudadanía, o qué competencia histórica se debe considerar deseable para cualquier ciudadano informado. Según encontramos en el prólogo, uno de los retos científicos del European Research Council es ofrecer soluciones para las sociedades inclusivas, innovadoras y reflexivas. Dicho reto solo se alcanzará con éxito si en las aulas se emplean métodos de enseñanza con los mismos atributos que se asignan a las sociedades. Nunca con clases que no traten la diversidad, se acomoden en la tradición o promuevan actividades con una respuesta única.

Como ya es consabido por la comunidad de profesores, en la última ley educativa española (LOMCE), los estándares de aprendizaje definen los conocimientos que el alumnado debería haber adquirido al finalizar su etapa educativa. En las asignaturas de Historia, estos estándares requeridos son un listado de contenidos, generalmente inabarcable y sin propuesta metodológica, que el profesorado tiene que incorporar en su programación y evaluar al final del curso. Los alumnos, por su parte, deben asimilar todo ese contenido del mismo modo que se ha venido haciendo de manera tradicional: memorizando datos. Los estudios realizados que se recogen en Enseñanza de la historia y competencias educativas ofrecen propuestas y herramientas a los docentes para que, aplicándolas a su práctica en las aulas, hagan que los alumnos descubran el pensamiento histórico y se conviertan en personas competentes - y no competitivas, como loablemente se menciona en la introducción del libro-. La solidaridad y la cooperación, tan necesarias en las sociedades presente y futura, están en el extremo opuesto de la competitividad de mercado y del individualismo en que incurre la «competencia financiera» evaluada por las pruebas PISA.

En el primer capítulo, de Jorge Sáiz y Jesús Domínguez, nos presentan diferentes conceptos metodológicos empleados como competencias históricas (las fuentes y las pruebas históricas; el tiempo histórico, el cambio y la continuidad; la relevancia histórica; la empatía histórica; la causalidad, las causas y las consecuencias; la dimensión ética; los relatos o las interpretaciones historiográficas; y el uso de la historia) y las destrezas cognitivas que requieren. La intención de los autores es ofrecer propuestas para la reflexión teórica y la elaboración de actividades en el aula, y lo materializan ofreciendo dos modelos de estas. Ambas trabajan partiendo del análisis de fuentes de información de distinta naturaleza y tipología para acabar ahondando en la relevancia histórica, en el caso del primer ejemplo, centrado en la importancia de la guerra civil española, y en la empatía histórica, en la segunda actividad, relativa a las causas originarias de la Primera Guerra Mundial.

El segundo capítulo, de Andrés Domínguez y Tania Rivero, de la Universidad de Santiago de Compostela, aborda las emociones como vehículo indispensable para el aprendizaje e incide en la formación del profesorado para llevarlo a cabo. En España, tras años de educación emocional para exaltar la patria y adoctrinar al alumnado, se optó por descartar las emociones en pro de un tratamiento puramente científico de las ciencias sociales, silenciando, de este modo, la fuerte carga emocional de las guerras europeas, la revolución industrial, la revolución rusa, la descolonización... Los autores demuestran, respaldados en rigurosos estudios de neurociencia, que la emoción permite una mejor asimilación de contenidos, y un estudio realizado en docentes en formación, que apuestan por la idoneidad de una enseñanza motivadoraemocional en las ciencias sociales, así lo constata. Sin embargo, son interesantes las reflexiones de esta muestra de futuros docentes sobre los principales obstáculos que se encuentran para implantar dicha metodología: falta de tiempo y excesiva exigencia de los currículos.

En torno al patrimonio cultural en la enseñanza y el aprendizaje de las ciencias sociales gira el tercer capítulo, escrito por Belén Castro y Ramón López. A través de dos acciones educativas, nos presentan cómo unir a la ciudadanía y al patrimonio cultural para la protección de este. Se per- 
sigue que la comunidad reconozca el valor de los elementos patrimoniales como referentes de su memoria, no tanto históricoartística como simbólica e identitaria. Se trata de desbancar al ciudadano pasivo que observa el patrimonio, para convertirlo en un actor clave que se implique y cree un vínculo afectivo con el acervo cultural. Se parte de la base de que el patrimonio es una construcción social; por tanto, es deber de la sociedad conocerlo y conservarlo para que no se pierda. Así, considerando a los alumnos miembros de esa sociedad, se presentan dos actividades realizadas en colegios de Pontevedra, donde se elaboró un proyecto con alumnos de $2^{\circ}$ y $3^{\circ}$ de la ESO para trabajar un patrimonio cercano, de su propia comunidad, con el objetivo de que los adolescentes valoren la importancia del patrimonio y sientan que les identifica y les pertenece.

Concepción Fuentes, Judit Sabido y J. Miquel Albert, del grupo DHIGECS de la Universidad de Barcelona, recogen, en el cuarto capítulo, siete ejemplos de unidades y recursos didácticos creados para trabajar la competencia social y ciudadana en la educación secundaria a partir del método del historiador, aplicando de manera adecuada la competencia digital. Es destacable la naturaleza flexible de los materiales presentados, tanto por su adaptación a la diversidad del alumnado como por la capacidad de traspasar competencias educativas.

La formación cívica es también el eje vertebrador del siguiente capítulo, presentado por Isidora Sáez, Josué Molina y Elvira Barriga. En él aplican los resultados de investigaciones anteriores para recomendar y promover la competencia social y ciudadana, ya que la conclusión de sus estudios sugiere que queda mucho trabajo por hacer en la apertura intercultural, la igualdad entre sexos y la participación política de los adolescentes. De nuevo, se demanda la formación del profesorado y el cambio en las leyes educativas para fomentar el trabajo democrático en las aulas, favoreciendo el diálogo, dándole valor al estudiante. Tenemos, como docentes, la oportunidad de aprovechar la potente influencia que ejerce la escuela en el desarrollo de la identidad durante la adolescencia.

El sexto capítulo, de Rodrigo Salazar-Jiménez, Cristian Orellana, Carlos Muñoz e
Ilaria Bellatti, invita a transformar el aula en un laboratorio para trabajar, mediante la técnica puzle de Aronson (los alumnos simulan ser expertos en diferentes campos dentro de un mismo grupo) y con el desarrollo del pensamiento histórico como objetivo, las consecuencias actuales de la guerra civil española en alumnos de $4^{\circ}$ de la ESO. De un modo bastante esquemático se dan las conclusiones desprendidas de la aplicación del juego de roles de la unidad elaborada, que principalmente permite al alumnado interpretar los hechos de la historia reciente desde distintos puntos de vista.

Los capítulos séptimo y octavo analizan las competencias históricas que se hallan, actualmente, en los libros de texto y en los exámenes de secundaria. El primero, de manos de Cosme J. Gómez, Raimundo A. Rodríguez y José Monteagudo, establece una muy interesante comparativa entre las actividades y las pruebas de evaluación en España y Reino Unido. La parte procedimental apenas se evalúa, en general, en los exámenes españoles, mientras que las pruebas evaluativas inglesas requieren de los alumnos - de manera, a nuestro gusto, admirable - reflexión y un adecuado uso de fuentes para trabajar distintos conceptos del pensamiento histórico. Las conclusiones se lamentan — ¿lo adivinan? - de los obstáculos legales para innovar en las aulas, cuando hay que cumplir un currículo tan extenso, y de la falta de formación del profesorado en los procesos evaluativos. Jesús Molina, Francisco J. Trigueros y Pedro Miralles, en el siguiente capítulo, también estudian el proceso de evaluación, pero desde el punto de vista del alumnado. Han diseñado un cuestionario para conocer la percepción de los estudiantes sobre la evaluación en la asignatura de Geografía e Historia y los resultados han confirmado que no se sienten implicados, ni siquiera informados, sobre el proceso evaluativo; que sus perspectivas de calificación suelen estar por encima de su nota final y que estudian, por lo general y como hemos hecho casi todos, poco antes del examen (teniendo en cuenta que el examen final suele tener un peso del $80 \%$ de la nota). Los autores reclaman un cambio en el modelo metodológico, que permita modificar los hábitos de los estudiantes con la finalidad de que integren las habilidades de un historiador en su aprendizaje.
Desde la Universidad de Murcia, Rita M. Matencio, Pedro Miralles y Francisca J. Serrano, abordan en el noveno capítulo la idoneidad que ofrecen las ciencias sociales para trabajar la diversidad cultural. A través de la citación de múltiples autores y estudios, el capítulo convida a abrir la puerta al conocimiento y reconocimiento de otras realidades culturales, distintas a la dominante, aprovechando la propia diversidad del aula, para formar ciudadanos capaces de relacionarse en una sociedad multicultural.

El último capítulo recoge las perspectivas de futuro de las competencias históricas en la enseñanza, escritas por los autores de la obra, y que pasan inexorablemente por un cambio en la metodología docente actual, para que el pensamiento y la conciencia histórica se instalen en las aulas definitivamente.

En la relación de los datos y conclusiones de los diferentes estudios, se han ofrecido herramientas para hacer partícipe, cuando no protagonista, al alumno de su propio aprendizaje. Parece obvio que el sujeto que aprende debiera ser el epicentro de todo cuanto rodea a la enseñanza, la razón de ser de profesores, leyes y currículos. Sin embargo, conclusión tras conclusión de los estudios presentados, encontramos a un alumno ajeno a las decisiones que marcan su aprendizaje, desvinculado de la materia que se imparte para que él se desarrolle como persona con espíritu crítico. Lo que importa, según parece tras hacer una fotografía al escenario educativo, es que el alumnado dé resultados cuantitativos satisfactorios. Difícilmente se trabaja y valora el crecimiento personal y emocional del discente. Si conseguimos llevar al aula cuestiones de índole problemática y aportamos las herramientas para su análisis, promoveremos la reflexión y el crecimiento de los alumnos.

Un libro que invita a reflexionar sobre la situación actual de la enseñanza de la historia $y$, a la vez, motiva al cuerpo docente para implantar cambios que mejorarán, indiscutiblemente, las capacidades del alumnado.

Nieves Vargas García Universitat de Barcelona 